\title{
Research on connection technology of prefabricated fabricated shear wall structure
}

\author{
Gao Su${ }^{1, a}$ \\ ${ }^{1}$ College of Construction Engineering, Nantong Vocational University, Nantong, Jiangsu226007,China \\ agaosu123@126.com
}

Keywords: shear wall; prefabricated assembly; node connection; residential industrialization

\begin{abstract}
In order to improve the concept of energy saving and emission reduction, and further promote the development of residential industrialization, the research of prefabricated shear wall structure has become a hot topic. This paper mainly analyzes the development of prefabricated wallboard structure, analysis of components and joints and joints of precast concrete shear wall structure connection, analysis of relevant research results at home and abroad in recent years, the seismic performance of joints, etc. combined with the shear wall are summarized. In this paper, the existing problems of prefabricated shear wall structure and seismic design are discussed, and the solutions and future research directions are pointed out.
\end{abstract}

\section{Introduction}

Prefabricated shear wall structure can promote the energy conservation and emission reduction of construction industry, and realize the industrialization of housing. The concrete construction of our country still using the traditional way of site construction, the degree of industrialization needs to be further improved, and will produce a large amount of energy consumption in the construction process of pollution is very serious, not the practice in the construction of energy-saving and environmental protection policy. With the help of prefabricated way, all materials can be prefabricated in the factory, and then complete the assembly at the scene, so that the residential industrialization in China continues to accelerate, the structure performance of buildings are protected, saving resources and energy, reduce construction waste, reduce the impact of various restrictions in the construction of the. In recent years, the research of prefabricated shear wall in our country is more thorough, and to some extent, it improves the functioning of the assembled structure. In 2012, China has established 27 national housing industrialization bases[1].

Shear wall structure is commonly used in high-rise residential buildings, and it is a common structure in high-rise residential buildings. Therefore, research on the appropriate prefabricated shear wall is the inevitable trend of the industrialization of the housing industry. Through the related research at home and abroad, it can be shown that the amount of horizontal joints of the fabricated shear wall is very large, so that the overall structure of the bearing capacity is very good, and its seismic capacity can also be improved. Therefore, the whole performance of the shear wall can be determined by improving the functioning of the joints and joints of the shear walls[2].

\section{The development of prefabricated wall panels at home and abroad}

In abroad, precast concrete shear wall structure are used in different building types, in European countries, prefabricated structure can be used in the 16-26 layer of the buildings, but the Japanese prefabricated shear wall can only be used in the 10 layer within the building, the structure in Japan can play a very seismic performance good. In the Mexico earthquake and the earthquake in Japan, because the local building fully with the concrete shear wall structure, so the building is almost not damaged, even if the building is damaged, can restore the user in a very short period of time. 
Prefabricated shear wall structure can better realize the industrialization of housing. As early as the late nineteenth Century, Europe first adopted this kind of structure, which was manifested in some projects, but the early prefabricated wall panels were usually made of non structural members. After World War II, housing tension in some European countries, so that Europe began to reform the housing industry, so that prefabricated structures have been used. In 1960s, the assembly type structure became the highest form of architecture in many countries[3].

In our country, prefabricated structure was put into use in 1950s, mainly used in large buildings, such as office buildings and industrial plants. However, then compare the prefabricated structure of our country's other single, but the technology is not mature, especially the waterproof technology is still relatively backward stage, the production of small businesses, this kind of structure is not used on a large scale. In twenty-first Century, the advantages of the prefabricated structure has been re excavated, and the concept of energy saving and emission reduction has been popular, prefabricated structure research in constant upgrading, is widely used in various construction projects[4].

\section{The performance and theoretical analysis of prefabricated shear wall structures abroad}

\section{Research on structural system}

In order to ensure the integrity of prefabricated structures, the Portland Cement Association carried out a number of column designs, and related studies were conducted on the basis of static loads. In the process of structure of a six story concrete shear wall in the analysis of the instantaneous load, in the process of simulation of instantaneous load, is used in the simulation of the explosion of the indoor gas, through the finite element analysis, to investigate the collapse resistance of the overall structure of the wall after the destruction. Through the analysis of relevant research results, it is found that the change of the corresponding dynamic factors is very large, and the corresponding average dynamic factors of the parameters will lead to damaging to the entire structure.

In the analysis of the seismic performance of multilayer precast concrete shear wall of the vertical joints, should be used to test, the Japanese building, for the vertical joints, in the analysis of experimental results, the load of precast concrete shear wall are influenced by many factors, and the influence of the ultimate load may be affected by the level of the joint. In the analysis of the finite element method, it is found that the influence of vertical joint precast shear walls on seismic performance is not particularly large, and is very similar to the basic cycle. Therefore, in the design of vertical joints, the shear capacity should be fully analyzed[5].

\section{Research on structural components}

In the case of unbounded concrete, the horizontal load performance of precast concrete walls is analyzed, and precast concrete walls are joined together by reinforcing bars across the horizontal joints during the test. In this experiment, the precast concrete wall mechanical properties were analyzed. The factors that precast concrete filled wall stress affect the performance, found the precast concrete wall in strength and stiffness with the cast-in-place concrete wall will not have too big difference, but its ductility is very ideal, even after the horizontal displacement the larger, does not cause great damage, the nature of this nonlinear is mainly decided by the level of the joint. In the establishment of the fiber element model, it is found that the periodic load is analyzed by the opening and closing of the joint, and it is found that the member will not be elastic.

\section{The advantages and disadvantages of prefabricated shear wall structures}

Prefabricated shear wall structures can be divided into 2 different types, one is partially prefabricated shear wall structure, and the other is fully prefabricated shear wall structure. Both of these two structures have their respective advantages and disadvantages. The shear walls in our country have been applied in diverse fields, and the fully prefabricated shear walls are an inevitable trend.

Showing the structure of a cast in a lot of prefabricated shear wall plug device, prefabricated shear wall structure is to connect many diverse prefabricated shear wall structure confined in the internal 
wall, so the need for cast-in-place prefabricated wall should continue to maintain and repair. The exterior wall is not very scrupulous about the bearing capacity, and the integrity of the structure of various prefabricated shear walls is very good, so that the connection performance can be ensured well. However, the internal precast shear wall also has its own problems, the level of mechanization in the construction process of the internal precast shear wall is not particularly high, non bearing wall will produce a lot of seams, resulting in leakage problem.

In the process of the entire prefabricated shear wall structure, the form of prefabricated component is fully adopted, and the bearing characteristics are displayed on the inner wall and the exterior wall. The mechanical level of the fully prefabricated shear wall structure is very prominent, and the efficiency of the construction can be guaranteed, but the drawback is that the process is very complicated in the process of splicing[6].

\section{The development of prefabricated wallboard structure in China}

Our country began to use prefabricated assembly structure in 1950s, and applied it in unfamiliar fields. In $80 \mathrm{~s}$, because of the complex structure of prefabricated assembly, and the small scale of enterprise, the form of enterprise operation was relatively simple, which led to this structure cannot be fully used. Now, the assembly structure has numerous benefits, the industrialization of housing and the concept of energy-saving emission reduction in-depth, prefabricated assembly structure has aroused great attention. Many pilot projects, such as Vanke Group, a lot of fabricated shear wall structures have been constructed, and the latest research results have been applied to them.

\section{Distributed shear reinforcement technology for fabricated shear walls}

Nowadays, the shear wall structure is widely used in industrialized houses, so as to realize the integrated structure. The past century, China mainly uses the concrete structure in the plug-in, assembly member not to maintain the structure of decoration, has now formed load-bearing shear wall structure. Assembly integral shear wall structure with cast-in-place core tube and cast-in-place wall, the shear wall structure and reinforced firmly connected together, so that the overall structure is more prominent, to improve the seismic performance of buildings. According to the analysis of various documents, there are mainly three kinds of connection methods for the reinforced concrete structure. They are mechanical connection, slurry anchor connection and steel sleeve connection.

\section{Mechanical connection technologies}

In the process of involuntary connection, it is mainly realized by the bite ability between the steel bar and the connecting piece, so as to ensure that the force between each steel bar is the same. Joining technology of mechanical steel bar began to rise in 1980s, which mainly adopt the sleeve extrusion joint and the taper thread joint. The main company is the American ERICO company, which mainly adopts the method of steel bar connection, and is commonly used in the building structure[7].

\section{Slurry anchor connection technology}

Bonding technology of grout anchor mainly adopts the method of indirect anchoring to realize the lap joint between the reinforcing bars, so as to ensure a certain distance between the steel bars. In the process of reinforcement lapping, it can also ensure that all parts of the building are lapped together, and the grouting material is transmitted by the great tensile force between the reinforcing bars, and then reinforced by the tangible way. The principle of this connection technology is very simple, and its requirements are not too high, and it has been extensively used in the construction industry. In the process of seismic performance test of prefabricated shear walls, the indirect lap joint method is applied to the reinforcing bars in the vertical direction, and this kind of mapping method can make the transmission stress of steel bars transmit very well. Through the analysis of the experimental results, after the tension occurs, the steel bars yield and the concrete breaks.

\section{Steel sleeves is grouting connection technology}

Steel sleeve grouting connection technology is in the process of machining the precast wall, in the upper and lower part of the embedding stirrup and sleeve together, which can form a high strength 
mortar, adding this structure. Using cement based grouting filling mode can assure the assembly structure is complete, will be in the casing connecting link in highly reinforced joints, so as to enhance the quality of grouting, to avoid any impact on the quality of grouting. By adjusting the embedded reinforcing bars on the upper part of the prefabricated wall panels, the hoisting work on site can be ensured and the follow-up work will be conducted smoothly. In the process of locating the embedded reinforcement bars, in the foundation structure, it is a need to ensure the verticality of the connections. If there is deviation in the process of locating the inserted tendon, the connection quality of the grouting joint will be damaged. The structure of the steel joint cannot show the effect, so the structure will have a certain negative impact in the process of force. For example, in Beijing's industrialized residential buildings, the shear wall structure is fully utilized[8].

\section{Problems to be studied}

Precast concrete shear wall structure has made remarkable progress, but there are still some problems. With the increasingly extensive application of precast concrete shear walls, the seismic performance of prefabricated concrete structures should be divided into separate areas. As a result of the earthquake plan in China continue to adjust, resulting in improved, seismic fortification criterion of original building continuously so that China should carry out further analysis on seismic performance of precast concrete shear wall, the seismic performance of this structure can directly affect the promotion and use of smooth.

Compared with the traditional assembled frame structure, the horizontal and vertical joints of prefabricated shear wall structures are prone to problems, resulting in leakage problems. Therefore, it is extremely important to choose the proper connection method, which can ensure the safety of prefabricated shear wall structure and ensure that it can work properly. Now in connection mode, mainly using wet connection, generally does not use dry connection way.

Cast-in-place shear wall has attracted wide attention at home and abroad, and also made a lot of structure of the experiment, China has carried out the steel frame and concrete filled steel tube columns and other experiments, results show that the shear wall with frame can improve the seismic performance, the overall seismic performance of the building has been improved. Therefore, we should adopt the concrete shear wall structure with borders. Now, the research on this problem is not deep enough in our country, and the joints, joints and integral members need further study.

Although our country has promulgated a large number of prefabricated shear wall specifications and standards, but still need in order to appear construction and design industry standards.

Precast concrete shear wall structure can promote the construction of China's resource-saving and environment-friendly society, also can realize energy saving and emission reduction construction, to further improve the rate of resource utilization, prevent the building have adverse impact on the environment, promote the construction industry in our country's further development. Although the prefabricated shear wall structure and connection technology to obtain certain development now, but many problems still need to be further explored, comparative framework of precast concrete shear wall structure and the traditional assembly type, mainly reflected in the connecting frame node and the vertical joints, is mainly used in wet or dry connection connection. Precast concrete shear wall structure should be implemented in more fields, and the level of seismic resistance should be improved. All these conclusions have to be concluded in practical research[9].

\section{References}

[1] Zhang H M, Lu X L, Duan Y F, et al. Experimental Study and Numerical Simulation of Partially Prefabricated Laminated Composite RC Walls[J]. Advances in Structural Engineering, 2011, 14(5):967-980.

[2]Sun J, Qiu H X. Seismic behavior and mechanism analysis of innovative precast shear wall involving vertical joints[J]. Journal of Central South University, 2015, 22(4):1536-1547. 
[3]Robeller C, Hahn B, Mayencourt P, et al. CNC-fabricated dovetails for Joints of Prefabricated CLT Components[J]. Bauingenieur, 2014, 89:487-490.

[4]Crocetti R, Sartori T, Flansbjer M. Timber-Concrete Composite Structures with Prefabricated FRC Slab[J]. Journal of Structural Engineering, 2014, 1(9).

[5]Lin C H, Tsai K C, Qu B, et al. Sub-structural pseudo-dynamic performance of two full-scale two-story steel plate shear walls[J]. Journal of Constructional Steel Research, 2010, 66(12):1467-1482.

[6]Farrow K T, Fleischman R B. Effect of Dimension and Detail on the Capacity of Precast Concrete Parking Structure Diaphragms[J]. Pci Journal, 2003, 48(5):46-61.

[7]Morang A, Waters J P, Stauble D K. Performance of Submerged Prefabricated Structures to Improve Sand Retention at Beach Nourishment Projects[J]. Journal of Coastal Research, 2014, 30(6):1140-1156.

[8]Zalewski D I S, Schacht D I G, Bachmann D I H. A contribution to the investigation of the shear-bearing capacity of;butt-jointed prefabricated columns with particular regard to an; extraordinary impact load[J]. Beton- Und Stahlbetonbau, 2013, 108(7):441-451.

[9]Isidor F, Brøndum K, Ravnholt G. The influence of post length and crown ferrule length on the resistance to cyclic loading of bovine teeth with prefabricated titanium posts[J]. International Journal of Prosthodontics, 1999, 12(1):78. 